\title{
Hubungan Dukungan Suami dengan Kesiapan Persalinan pada Ibu Hamil Usia Remaja di Sukowono, Jember
}

\section{(The relationship between Husband's Support and Childbirth Readiness of Teenage Pregnant Women in Sukowono, Jember)}

\author{
Iya Farida, Dini Kurniawati, Peni Perdani Juliningrum \\ Program Studi IImu Keperawatan Fakultas Keperawatan Universitas Jember \\ Jln. Kalimantan 37, Jember 68121 \\ e-mail: ilyafarida270@gmail.com
}

\begin{abstract}
Childbirth readiness is a birth planning process and anticipation of actions to prevent complications. Teenage pregnant women ( $<20$ years) are at risk because at that age the productive and mental functions are immature. This study aimed to analyze the relationship between husband's support and childbirth readiness of teenage pregnant women in Sukowono Community Health Center, Jember. The study used correlational approach with cross-sectional study design. Sample size was 34 teenage pregnant women, collected using total sampling. Data was obtained by using questionnaire of husband's support (validity: 0.759-0.820 and reliability: 0.789) and childbirth readiness (validity: 0.488-0.835 and reliability 0.957). Data analysis used the spearman test. The study showed that the respondents had less husband support, i.e. 19 people and the childbirth readiness was 20 people. The results showed that there was a relationship between husband's support and childbirth readiness ( $p$ value $=0,000)$ and $h$ $r=0,623$. This study indicated that the higher of husband's support which receive by pregnant women, the higher of the childbirth readiness. Teenage pregnant women who have good husband's support will prepare mature labor plan, and further provides safety to mother and fetus.
\end{abstract}

Keywords: Husband's support, Childbirth readiness, Adolescent pregnant women

\begin{abstract}
Abstrak
Kesiapan persalinan merupakan proses perencanaan kelahiran dan antisipasi tindakan untuk mencegah terjadinya komplikasi. Ibu hamil usia remaja ( $<20$ tahun) termasuk kelompok berisiko karena pada usia tersebut fungsi reproduksi dan mental belum matang. Penelitian ini bertujuan untuk menganalisis hubungan dukungan suami dengan kesiapan persalinan pada ibu hamil usia remaja di wilayah kerja Puskesmas Sukowono Kabupaten Jember. Penelitian ini menggunakan korelasional dengan rancangan penelitian cross sectional. Besar sampel 34 ibu hamil usia remaja menggunakan total sampling. Data diperoleh dengan menggunakan kuesioner dukungan suami (validitas: 0,759-0,820 dan reliabilitas: 0,789) dan kuesioner kesiapan persalinan (validitas: 0,488-0,835 dan reliabilitas: 0,957). Analisis data menggunakan uji spearman. Hasil penelitian menunjukkan bahwa responden mendapatkan dukungan suami kurang yaitu 19 orang dan kesiapan persalinan kategori siap yaitu 20 orang. Hasil penelitian menunjukkan ada hubungan antara dukungan suami dengan kesiapan persalinan $(p$-value $=0,000)$ dan kekuatan $(r=0,623)$. Penelitian ini menunjukkan bahwa semakin tinggi dukungan suami yang diterima ibu hamil, maka semakin tinggi kesiapan persalinan. Ibu hamil usia remaja yang memiliki dukungan suami yang baik akan mempersiapkan rencana dan program persalinan yang lebih matang, sehingga persalinan ibu hamil lancar dan memberikan keselamatan pada ibu dan janin.
\end{abstract}

Kata kunci: Dukungan suami, Kesiapan persalinan, Ibu hamil remaja 


\section{Pendahuluan}

Kesiapan persalinan merupakan proses perencanaan kelahiran normal dan antisipasi tindakan apabila terjadi komplikasi saat persalinan atau dalam keadaan darurat $[1,2]$. Kesiapan persalinan dapat dipengaruhi oleh usia ibu hamil [3]. Usia ibu dibawah 20 tahun menunjukkan fungsi reproduksi yang belum matang dan secara mental belum siap menghadapi kehamilan sehingga berisiko terjadi gangguan saat kehamilan, proses persalinan, dan berdampak pada persiapan persalinan yang kurang [4]. Kehamilan pada remaja menimbulkan risiko psikologis mengenai kesiapan dan penyesuaian diri terhadap peran baru menjadi seorang ibu. Transisi menjadi orang tua menjadi sulit bagi ibu remaja karena tugas perkembangan orang tua yang belum terpenuhi [5].

Data BKKBN 2015 jumlah remaja perempuan di Jawa Timur yang berusia kurang dari 16 tahun telah menikah atau hamil mencapai 5 ribu orang [6]. Berdasarkan analisis laporan Badan Pemberdayaan Perempuan dan Keluarga Berencana (BPPKB) Kabupaten Jember 2015 menyebutkan kecamatan penyumbang terbesar pernikahan dini yaitu Kecamatan Sukowono (81,42\% pernikahan) [7]. Remaja perempuan di Kecamatan Sukowono yang menikah diusia kurang dari 20 tahun yaitu 364 remaja pada tahun 2016 meningkat menjadi 403 remaja di tahun 2017. Data bulan Oktober 2018 terdapat 34 ibu hamil usia remaja trimester III di wilayah kerja Puskesmas Sukowono dengan rentang usia 16-19 tahun.

Kesiapan persalinan dibagi menjadi kesiapan fisik, psikologis, finansial, dan budaya [8]. Faktor-faktor yang mempengaruhi kesiapan persalinan pada ibu hamil yaitu umur, paritas, pengalaman dan pendidikan, dukungan keluarga, dukungan suami, dan dukungan tenaga kesehatan $[9,10]$. Peran suami meliputi aspek produktif dan aspek reproduktif. Aspek produktif suami sebagai pencari nafkah dan mempersiapkan biaya persalinan, sedangkan aspek reproduktif suami ikut merawat kehamilan dan meminta bantuan saat persalinan. Banyak ibu meninggal karena terlambat mendapatkan pertolongan atau pertolongan pertama secara sederhana diberikan kurang memadai dikarenakan suami tidak memahami adanya masalah saat kehamilan dan persalinan [11].

Dukungan suami untuk meningkatkan kesiapan ibu dalam menghadapi proses persalinan yaitu dengan memberikan perhatian dan membina hubungan yang baik dengan ibu hamil sehingga ibu dapat mengungkapkan apa yang dirasakan kepada suaminya. Keberadaan dukungan suami diharapkan agar ibu merasakan ketenangan sehingga ibu dapat menghadapi proses persalinan dengan lancar [12-14].

Tujuan dari penelitian ini untuk mengetahui hubungan dukungan suami dengan kesiapan persalinan pada ibu hamil usia remaja di Wilayah Kerja Puskesmas Sukowono Kabupaten Jember.

\section{Metode Penelitian}

Desain penelitian dalam penelitian ini menggunakan korelasional dengan rancangan cross-sectional. Sampel dalam penelitian ini sebanyak 34 ibu hamil usia remaja yang tinggal bersama suaminya.

Pengambilan data dilakukan pada bulan Januari 2019. Instrumen penelitian yang digunakan berupa kuesioner Dukungan Suami (17 pernyataan) dan Kesiapan Persalinan (28 pernyataan). Analisis data bivariat menggunakan uji Spearman.

\section{Hasil}

Hasil karakteristik responden dapat dilihat pada tabel 1.

Tabel 1. Karakteristik Responden Berdasarkan Usia Ibu Hamil, Usia Suami, dan Usia Kehamilan

\begin{tabular}{lcc}
\hline \multicolumn{1}{c}{ Variabel } & Median & Min - Maks \\
\hline Usia ibu hamil & 18 & $16-19$ \\
\hline Usia suami & 25 & $19-40$ \\
\hline Usia kehamilan & 8 & $7-9$ \\
\hline
\end{tabular}

Sumber : Data Primer Peneliti, Januari 2019

Berdasarkan tabel 1 menunjukkan bahwa dari 34 responden menurut nilai tengah usia ibu hamil yaitu 18 tahun dengan nilai minimal 16 tahun dan nilai maksimal 19 tahun. Nilai tengah usia suami yaitu 25 tahun dengan nilai minimal 19 tahun dan nilai maksimal 40 tahun. Nilai tengah usia kehamilan yaitu usia 8 bulan dengan nilai minimal 7 bulan dan nilai maksimal 9 bulan.

Tabel 2. Karakteristik Responden Berdasarkan Status Pernikahan Suami Sebelumnya, Tingkat pendidikan Responden dan Suami, Pekerjaan Responden dan Suami, Pendapatan, Suku Responden dan Suami, dan 
Farida, et al., Hubungan Dukungan Suami dengan Kesiapan Persalinan pada Ibu Hamil .....

Alasan Menikah Dini

\begin{tabular}{|c|c|c|}
\hline Variabel & Frekuensi & Persentase \\
\hline \multicolumn{3}{|l|}{ Status Pernikahan } \\
\hline \multicolumn{3}{|l|}{ Suami Sebelumnya } \\
\hline Belum Menikah & 29 & 85,3 \\
\hline Duda & 5 & 14,7 \\
\hline \multicolumn{3}{|l|}{ Tingkat Pendidikan } \\
\hline \multicolumn{3}{|l|}{ Ibu Hamil } \\
\hline SD & 13 & 38,2 \\
\hline SMP & 18 & 52,9 \\
\hline SMA & 3 & 8,8 \\
\hline \multicolumn{3}{|l|}{ Tingkat Pendidikan } \\
\hline \multicolumn{3}{|l|}{ Suami } \\
\hline SD & 11 & 32,4 \\
\hline SMP & 13 & 38,2 \\
\hline SMA & 10 & 29,4 \\
\hline \multicolumn{3}{|l|}{ Pekerjaan Suami } \\
\hline Wiraswasta & 16 & 47,1 \\
\hline Petani & 13 & 38,2 \\
\hline Buruh & 3 & 8,8 \\
\hline Tidak bekerja & 2 & 5,9 \\
\hline \multicolumn{3}{|l|}{ Pendapatan } \\
\hline < Rp2.170.917,- & 33 & 97,1 \\
\hline > Rp2.170.917,- & 11 & 2,9 \\
\hline \multicolumn{3}{|l|}{ Suku Ibu Hamil } \\
\hline Jawa & 11 & 32,4 \\
\hline Madura & 23 & 67,6 \\
\hline \multicolumn{3}{|l|}{ Suku Suami } \\
\hline Jawa & 9 & 26,5 \\
\hline Madura & 25 & 73,5 \\
\hline \multicolumn{3}{|l|}{ Alasan Menikah Dini } \\
\hline Perjodohan & 13 & 38,2 \\
\hline Keinginan pribadi & 21 & 61,8 \\
\hline
\end{tabular}

Sumber : Data Primer Peneliti, Januari 2019

Berdasarkan tabel 2 menunjukkan bahwa status pernikahan suami sebelumnya sebagian besar yaitu belum menikah berjumlah 29 orang $(85,3 \%)$. Tingkat pendidikan ibu hamil paling banyak SMP sejumlah 18 orang $(52,9 \%)$ dan tingkat pendidikan suami paling banyak SMP sejumlah 13 orang $(38,2 \%)$. Jenis pekerjaan suami paling banyak yaitu wiraswasta 16 orang $(47,1 \%)$. Sebagian besar pendapatan yang diperoleh < Rp2.170.917,- yaitu 33 orang $(97,1 \%)$. Suku ibu hamil paling banyak Suku Madura yaitu 25 orang $(67,6 \%)$ dan suku suami paling banyak Suku Madura yaitu 21 orang $(73,5 \%)$. Alasan menikah dini yang paling banyak didapatkan pada ibu hamil usia remaja adalah keinginan sendiri 21 orang $(61,8 \%)$.
Tabel 3. Indikator Dukungan Suami pada Ibu Hamil Usia Remaja

\begin{tabular}{llllll}
\hline No & $\begin{array}{c}\text { Indikator } \\
\text { dukungan } \\
\text { suami }\end{array}$ & \multicolumn{2}{c}{ Baik } & \multicolumn{2}{c}{ Kurang } \\
\cline { 3 - 6 } & $\mathrm{N}$ & $\%$ & $\mathrm{~N}$ & $\%$ \\
\hline 1 & Instrumental & 15 & 44,1 & 19 & 55,9 \\
\hline 2 & Informasional & 22 & 64,7 & 12 & 35,3 \\
\hline 3 & $\begin{array}{c}\text { Emosional } \\
\text { dan penilaian }\end{array}$ & 17 & 50 & 17 & 50 \\
\multicolumn{3}{c}{ Sumber: Data Primer Peneliti, Januari 2019}
\end{tabular}

Berdasarkan tabel 3 didapatkan nilai indikator dukungan suami paling tinggi pada indikator informasional dengan jumlah 22 orang $(64,7 \%)$ dalam kategori baik dan indikator paling rendah yaitu indikator instrumental dengan jumlah 15 orang $(44,1 \%)$ dalam kategori baik.

Tabel 4. Distribusi Dukungan Suami pada Ibu Hamil Usia Remaja

\begin{tabular}{|c|c|c|}
\hline $\begin{array}{c}\text { Variabel } \\
\text { dukungan suami }\end{array}$ & Jumlah & $\begin{array}{c}\text { Persentase } \\
(\%)\end{array}$ \\
\hline Baik & 15 & 44,1 \\
\hline Kurang & 19 & 55,9 \\
\hline Total & 34 & 100 \\
\hline \multicolumn{3}{|c|}{ Sumber: Data Primer Pribadi, Januari 2019} \\
\hline $\begin{array}{l}\text { Berdasarka } \\
\text { dukungan suami } \\
\text { wilayah kerja } P \\
\text { banyak dalam kat } \\
19 \text { orang }(55,9 \%)\end{array}$ & $\begin{array}{l}\text { tabel } \\
\text { da ibu } \\
\text { esmas } \\
\text { ri dukuns }\end{array}$ & $\begin{array}{l}\text { menunjukkan } \\
\text { il remaja di } \\
\text { wono paling } \\
\text { suami kurang }\end{array}$ \\
\hline
\end{tabular}

Tabel 5. Indikator Kesiapan Persalinan pada Ibu Hamil Usia Remaja

\begin{tabular}{lllccc}
\hline No & $\begin{array}{l}\text { Indikator } \\
\text { Kesiapan }\end{array}$ & \multicolumn{2}{c}{ Siap } & \multicolumn{2}{c}{$\begin{array}{c}\text { Tidak } \\
\text { siap }\end{array}$} \\
\cline { 3 - 6 } & persalinan & & & \multicolumn{3}{c}{$\%$} & $\mathrm{~N}$ & $\%$ \\
\hline 1 & Fisik & 23 & 67,6 & 11 & 32,4 \\
\hline 2 & Psikologis & 22 & 55,9 & 15 & 44,1 \\
\hline 3 & Finansial & 17 & 50 & 17 & 50 \\
\hline 4 & Budaya & 28 & 82,4 & 6 & 17,6 \\
\hline
\end{tabular}

Sumber: Data Primer Peneliti, Januari 2019

Berdasarkan tabel 5 didapatkan nilai indikator kesiapan persalinan paling tinggi pada indikator budaya dengan jumlah 28 orang $(82,4 \%)$ dalam kategori siap dan indikator paling rendah yaitu indikator finansial dengan jumlah 17 orang $(50 \%)$ dalam kategori siap. 
Tabel 6. Distribusi Kesiapan Persalinan pada Ibu Hamil Usia Remaja

\begin{tabular}{lcc}
\hline $\begin{array}{c}\text { Variabel } \\
\text { Kesiapan } \\
\text { persalinan }\end{array}$ & Jumlah & $\begin{array}{c}\text { Persentase } \\
(\%)\end{array}$ \\
\hline Siap & 20 & 58,8 \\
\hline Tidak siap & 14 & 41,2 \\
\hline Total & 34 & 100 \\
\hline Sumber: Data Primer Peneliti, Januari 2019
\end{tabular}

Sumber: Data Primer Peneliti, Januari 2019

Berdasarkan tabel 6 menunjukkan bahwa kesiapan persalinan pada ibu hamil remaja di wilayah kerja Puskesmas Sukowono dalam katergori siap sebanyak 20 orang $(58,8 \%)$.

Tabel 7. Hasil Analisis Hubungan Dukungan Suami dengan Kesiapan Persalinan pada Ibu Hamil Usia Remaja

\begin{tabular}{|c|c|c|}
\hline Variabel & & $\begin{array}{c}\text { Dukungan } \\
\text { suami }\end{array}$ \\
\hline Kesiapan persalinan & $r$ & 0,623 \\
\hline & $p$ value & 0,000 \\
\hline
\end{tabular}

Sumber: Data Primer Peneliti, Januari 2019

Berdasarkan tabel 7 menunjukkan hasil statistik menggunakan uji korelasi spearman didapatkan $p$ value $=0,000$ yang memiliki arti bahwa Ha diterima sehingga dapat diartikan bahwa terdapat korelasi antara dukungan suami dengan kesiapan persalinan.

\section{Pembahasan \\ Karakteristik Responden}

Hasil penelitian menunjukkan bahwa usia ibu hamil tergolong dalam kategori remaja akhir. Pertumbuhan dan fungsi reproduktif pada remaja akhir semakin lengkap dan telah belajar meninjau masalah lebih komprehensif serta telah mampu membentuk hubungan yang lebih stabil dengan orang lain [15]. Penelitian sebelumnya menjelaskan bahwa kehamilan pada remaja dapat menimbulkan risiko psikologis mengenai kesiapan dan penyesuaian diri terhadap peran baru menjadi seorang ibu [16]. Usia ibu yang cukup dalam mengawali kehamilan membantu ibu dalam kematangan menghadapi persoalan baik menghadapi kehamilan dan perubahan ketika hamil [17].

Usia suami menunjukkan bahwa tergolong dalam kategori dewasa awal. Pada dewasa awal, seseorang harus mampu beradaptasi dengan pengalaman yang baru dan mengarahkan pada keinginan serta tanggung jawab yang belum dilakukan sewaktu remaja [15]. Suami yang berusia matang atau dewasa semaksimal mungkin akan memberikan dukungan dan mendampingi istri. Hal ini dikarenakan kematangan usia suami mampu memahami kondisi psikologi saat istri hamil dan menghadapi persalinan [18].

Status pernikahan suami sebelumnya pada penelitian ini sebagian besar belum menikah dan sedikit suami berstatus duda. Pernikahan duda dengan gadis dapat memberikan dampak positif yaitu bagi umur suami yang lebih tua maka dapat berpikir secara matang, berperilaku lebih tegas, dan mampu menyelesaikan masalah dengan pikiran yang sehat [19].

Usia kehamilan ibu hamil yaitu 7 sampai 9 bulan yang termasuk dalam kehamilan trimester tiga (28 sampai 40 minggu). Kehamilan trimester tiga merupakan periode menunggu kelahiran bayi, ibu mulai khawatir terhadap diri dan bayinya, dan saat itu juga merupakan persiapan yang aktif dalam menunggu kelahiran [20].

Ibu hamil usia remaja pada penelitian ini paling banyak berpendidikan SMP. Pendidikan diperlukan ibu hamil agar lebih tanggap apabila ada indikasi kehamilan atau persalinan yang bermasalah sehingga dapat cepat dalam mengambil keputusan [17].

Pendidikan suami paling banyak berpendidikan SMP. Suami yang memiliki pengetahuan rendah menyebabkan kurangnya pemahaman adanya tanda bahaya dan komplikasi obstetrik dalam kehamilan dan persalinan sehingga pertolongan yang diberikan kepada istri akan terhambat [21].

Hasil penelitian menjelaskan bahwa semua ibu hamil remaja merupakan ibu rumah tangga. Semakin tinggi pendidikan ibu hamil, maka semakin baik perencanaan persalinannya [22]. Semakin baik pengetahuan dan sikap pada ibu hamil maka semakin baik kesiapan dalam menghadapi persalinan [23].

Pekerjaan suami pada penelitian ini paling banyak sebagai wiraswasta. Penelitian sebelumnya menjelaskan bahwa jenis pekerjaan suami juga mempengaruhi perilaku kesehatan ibu hamil, suami jenis pekerjaan wiraswasta memiliki perilaku baik lebih tinggi dibandingkan suami pekerja bebas [24]. Friedman 1998 menjelaskan bahwa kepala keluarga berperan penting dalam meningkatkan pendapatan untuk mencukupi kebutuhan keluarga dan sebagai cara mengembangkan kemampuan individu 
[25].

Hasil penelitian menunjukkan pendapatan sebagian besar <Rp2.170.917,-. Pendapatan yang cukup akan membuat ibu lebih siap menjalani kehamilan karena kehamilan memerlukan biaya seperti pemenuhan makanan bergizi untuk ibu dan janin, pakaian ibu hamil, biaya untuk persalinan dan kebutuhan bayi setelah lahir [2].

Suku ibu hamil dan suami paling banyak adalah Suku Madura. Penelitian sebelumnya menjelaskan bahwa perawatan kehamilan Budaya Madura melibatkan peran serta orang tua atau mertua dalam mengambil keputusan selama masa kehamilan. Pengaruh budaya atau adat istiadat Madura seperti adanya mitos kehamilan atau pantangan yang harus dilakukan oleh ibu hamil [26].

Alasan menikah dini paling banyak dalam penelitian ini adalah keinginan pribadi. Penelitian sebelumnya menunjukkan hasil wawancara dengan remaja yang menikah dini yaitu separuh dari responden dalam penelitian memutuskan menikah karena keinginan sendiri. Remaja yang memutuskan menikah dikarenakan ingin bersama dengan laki-laki yang dicintainya dan tidak mempertimbangan kemungkinan risiko yang akan terjadi [27].

\section{Dukungan Suami}

Ibu hamil remaja paling banyak mendapatkan dukungan suami kurang dalam penelitian ini. Kehadiran suami dalam memenuhi kebutuhan fisik dan psikis saat istri hamil sangat penting terutama pada ibu remaja yang merupakan kehamilan anak pertama. Sebab pada ibu hamil remaja, ibu belum paham dan belum memiliki pengalaman dibandingkan dengan ibu hamil dewasa. Ibu hamil remaja cenderung memiliki kecemasan, depresi, dan agresi lebih tingi dibandingkan dengan kehamilan pada orang dewasa [28]. Oleh karena itu diperlukan dukungan suami dalam kehamilan, karena perilaku suami yang baik bisa membuat ibu hamil merasakan ketenangan dalam menjalani kehamilan.

Indikator dukungan suami paling tinggi pada penelitian ini adalah indikator dukungan informasional. Penelitian sebelumnya menunjukkan dukungan informasional merupakan dukungan tertinggi dibandingkan dengan indikator yang lain [29]. Usia ibu hamil kurang dari 20 tahun dengan tingkat pendidikan yang rendah dan sedang menghadapi kehamilan pertama tentu belum memiliki pengalaman, oleh sebab itu sangat membutuhkan informasi terkait kehamilannya. Indikator informasional merupakan indikator tertinggi pada variabel dukungan suami pada penelitian ini. Hal ini dimungkinkan berkaitandengan suami yang berusaha mencari informasi kehamilan kepada orang yang lebih berpengalaman dan kemudian memberikan saran kepada ibu remaja.

Indikator dukungan suami paling rendah pada penelitian ini adalah indikator dukungan instrumental. Penelitian sebelumnya menunjukkan bahwa dukungan instrumental menjadi indikator terendah pada ibu hamil dalam menghadapi persalinan [30]. Dukungan suami merupakan salah satu bentuk interaksi yang didalamnya termasuk hubungan saling memberi dan menerima perlindungan yang nyata, perlindungan tersebut membuat seseorang memberikan cinta, perhatian, dan merasakan keterkaitan yang baik bagi pasangan [31]. Indikator instrumental merupakan indikator terendah pada variabel dukungan suami pada penelitian ini. Hal ini dimungkinkan berkaitan dengan kesibukan suami dalam mencari nafkah sehingga suami kurang memperhatikan kebutuhan istri secara fisik.

\section{Kesiapan Persalinan}

Hasil penelitian menunjukkan kesiapan persalinan pada ibu hamil usia remaja lebih dari separuh tergolong siap. Persiapan persalinan pada ibu hamil remaja yang adekuat dapat mengurangi rasa takut menjelang persalinan serta memudahkan ibu beradaptasi dengan peran barunya [32].

Indikator kesiapan persalinan paling tinggi pada penelitian ini adalah kesiapan budaya. Meskipun perilaku budaya dalam persiapan persalinan di daerah pedesaan masih ada, seperti pantangan makan dan larangan dalam mempersiapkan persalinan. Sebagian besar ibu hamil remaja percaya bahwa hal tersebut hanya mitos-mitos yang sudah sejak dahulu dipercaya, namun rasa takut yang ada dipikiran ibu hamil membuat beberapa ibu hamil remaja terpaksa untuk melakukan pantangan makanan tersebut. Perubahan perilaku melalui pemberian informasi dilakukan oleh petugas kesehatan untuk mendorong perilaku positif ibu hamil. Hampir seluruh reponden merasakan peran dari petugas kesehatan dan menyadari bahwa informasi yang diberikan adalah penting, sehingga ibu hamil menerima masukan dari petugas kesehatan seperti pantangan makanan yang diperbolehkan. Hal tersebut membuktikan bahwa meskipun budaya ada dalam ibu hamil 
namun dengan memiliki pikiran terbuka terkait informasi pada ibu hamil remaja dapat meningkatkan perilaku positif dalam kehamilan.

Perawatan kehamilan Budaya Madura yaitu adanya keterlibatan orang tua atau mertua dalam mengambil peran selama masa kehamilan [26]. Kepercayaan orang tua tersebut dapat diterima oleh beberapa ibu hamil usia remaja sehingga ada beberapa ibu hamil masih mempercayai mitos yang muncul. Ibu hamil tidak diperbolehkan mengkonsumsi terong dan udang karena dikhawatirkan bayi tidak akan keluar saat proses persalinan. Ibu hamil dilarang mengkonsumsi air es karena dianggap bahwa air es dapat membesarkan janin sehingga menyebabkan persalinan menjadi sulit. Larangan dalam mempersiapkan kelahiran anak juga temui pada penelitian ini, apabila ibu hamil dan suami telah mempersiapkan kelahiran anak sebelum anak lahir akan mengakibatkan anak yang dilahirkan akan meninggal. Persiapan persalinan perlu dilakukan untuk membantu proses persalinan yang lancar.

Indikator kesiapan persalinan paling rendah adalah kesiapan finansial. Kesiapan finansial merupakan keperluan yang mutlak yang harus dipersiapkan oleh ibu yang akan melahirkan. Persiapan ini membutuhkan biaya yang cukup, oleh karena itu ibu hamil dan suami sebaiknya sudah memperhitungkan dan mempersiapkan biaya untuk persalinan [2]. Indikator kesiapan finansial merupakan indikator terendah pada variabel kesiapan persalinan pada penelitian ini. Hal ini dimungkinkan berkaitan dengan pendapatan yang sebagian besar <Rp2.170.917,- dan pendapatan tersebut dipergunakan untuk mencukupi kebutuhan sehari-hari.

\section{Hubungan Dukungan Suami dengan Kesiapan Persalinan pada Ibu Hamil usia Remaja}

Hasil penelitian menunjukkan bahwa dukungan suami dan kesiapan persalinan pada ibu hamil usia remaja memiliki hubungan yang bermakna dengan arah hubungan yang positif dan kekuatan hubungan yang kuat. Sehingga dapat disimpulkan yaitu semakin tinggi dukungan suami, maka semakin tinggi kesiapan persalinan pada ibu hamil remaja.

Ibu hamil usia remaja memiliki tingkat kematangan pikiran dan perilaku yang masih kurang dalam menghadapi perubahan dan penyesuaian kehamilan. Semakin muda usia ibu maka semakin kurang kepedulian dan pengalaman yang dimiliki ibu hamil karena ketidaksiapan ibu remaja dalam kehamilan [33]. Dukungan suami menjadi salah satu faktor dalam menentukan proses pengambilan keputusan mengenai kesiapan persalinan yang direncanakan [17]. Dukungan yang diberikan suami kepada ibu dapat menimbulkan ketenangan batin dan perasaan senang sehinga menimbulkan sikap positif terhadap diri dan kehamilannya [17].

\section{Simpulan dan Saran}

Penelitian ini menyimpulkan adanya hubungan antara dukungan suami dengan kesiapan persalinan pada ibu hamil usia remaja di wilayah kerja Puskesmas Sukowono Kabupaten Jember. Penelitian ini menunjukkan lebih dari separuh ibu hamil usia remaja memiliki dukungan suami yang kurang dan lebih dari separuh ibu hamil usia remaja memiliki kesiapan persalinan dalam kategori siap.

Bagi instansi pendidikan keperawatan dan pelayanan kesehatan perlu disosialisasikan tentang pentingnya kesiapan persalinan yang tidak hanya berfokus pada ibu hamil usia remaja, namun kepada anggota keluarga khususnya suami. Dukungan suami pada ibu hamil penting dilakukan karena suami adalah pengambil keputusan dalam keluarga terutama mengenai kehamilan hingga persalinan.

\section{Ucapan Terima Kasih}

Penulis mengucapkan terima kasih kepada pihak-pihak terkait khususnya bidan, sekretaris bidan dan kader kesehatan di wilayah kerja Puskesmas Sukowono yang telah membantu proses penelitian.

\section{Daftar Pustaka}

[1] Hailu M, Gebremariam A, Alemseged F, Deribe K. Birth Preparedness and Complication Readiness among Pregnant Women in Southern Ethiopia. Plos One. 2011; 6(6).

[2] Rosyidah SS. Faktor yang Berhubungan dengan Kesiapan Persalinan pada Ibu Hamil Trimester III Di Puskesmas Pleret Bantul. Naskah Publikasi. Yogyakarta: Fakultas IImu Kesehatan Universitas 'Aisyiyah Yogyakarta; 2017.

[3] Gitayanti R. Pengalaman Kehamilan Perempuan Primigravida dengan Riwayat Menikah Usia Dini di Desa Baletbaru Kecamatan Sukowono Kabupaten. e-Jurnal Pustaka Kesehatan. 2016; 4 (1):1-6.

[4] Permatasari A. Hubungan antara 
Pengetahuan Faktor Risiko Kehamilan dan Jenis Persalinan di RSUD dr. Moewardi. Skripsi. Surakarta: Fakultas Kedokteran Universitas Sebelas Maret; 2012.

[5] Rahmawati JK. Penerimaan Diri Remaja Hamil Pra Nikah. Naskah Publikasi. Bandung: Universitas Pendidikan Indonesia; 2014.

[6] Amaluddin. Pernikahan Usia Dini di Jawa Timur. [Internet]. Metro TV News.com; 21 Oktober 2018. [serial online] Available from: http://jatim.metrotvnews.com/peristiwa/wkB 805DN-pernikahan-usia-dini-di-surabayatertinggi-se-jawa-timur

[7] Rohmati. Implementasi Program Bina Keluarga Remaja (BKR) dalam Penurunan Angka Pernikahan Dini di Kecamatan Sukowono Kabupaten Jember. Skripsi. Jember: Fakultas Kesehatan Masyarakat Universitas Jember; 2016.

[8] Purwadi LK, Krismayani I. Kemampuan Literasi Informasi lbu Hamil dalam Persiapan Persalinan di Kecamatan Wonosobo. Jurusan IImu Perpustakaan. 2016; 1-10.

[9] Zamriati WE, Hutagaol E, Ferdinand, W. Faktor-Faktor yang Berhubungan dengan Kecemasan Ibu Hamil Menjelang Persalinan di Poli Kia PKM Tuminting, Journal Keperawatan (e-Kp). 2013; 1(1):17.

[10] Arifin A, Kundre R, Rompas S. Hubungan Dukungan Keluarga dengan Kecemasan Ibu Hamil Menghadapi Proses Persalinan di Puskesmas Budilatama Kecamatan Gadung Kabupaten Buol Propinsi Sulawesi Tengah. eJournal Keperawatan (e-Kp). 2015; 3(2): 1-7.

[11] Keumalahayati. Dukungan Suami terhadap Kesiapan Ibu Primigravida menghadapi Persalinan di Daerah Pedesaan di Langsa Nanggroe Aceh Darussalam: Study Grounded Theory. Skripsi. Depok: Fakultas Ilmu Keperawatan Universitas Indonesia; 2008.

[12] Melinda M, Indriyani D. Hubungan Dukungan Suami dengan Kesiapan Psikologis Ibu Bersalin pada Kondisi Postdate di RSIA Srikandi IBI Jember, 2014. Jember: Universitas Muhammadiyah Jember; 2014.

[13] Yuliana A. Dukungan Suami pada Ibu Hamil dalam Menghadapi Masa Persalinan di Desa Joho Kabupaten Sukoharjo. Maternity : Jurnal Kebidanan dan IImu Kesehatan. 2015; 2(2):1-7.
[14] Chomaira N. Five in One, The Series of pregnancy (Panduan Terlengkap Kehamilan) Persiapan Kehamilan. Jakarta: PT Elex Media Komputindo; 2012.

[15] Potter PA, Perry AG. Fundamental of Nursing, 7th Edition. Singapura: Elsevier's Health Science Rights Departement. A, Ferderika, N. 2010. Fundamental Keperawatan. Edisi 7. Jakarta:Selemba Medika; 2010.

[16] Arianiyani M, Kamilia F. Penyesuain Diri Pada Remaja yang Menjadi Ibu. Jurnal Penelitian dan Pengukuran Psikologi. 2015; 4(1): 1-5.

[17] Johnson JY. Maternal-Newborn Nursing Demystified. Keperawatan Maternitas Demystified. Edisi 1. Yogyakarta: Rapha Publishing; 2014.

[18] Retnowati. Hubungan antara Dukungan Suami dengan Kecemasan saat Persalinan pada Ibu Primigravida di Puskesmas Mlati II Kabupaten Sleman. Skripsi. Yogyakarta: Program Studi IImu Keperawatan Sekolah Tinggi Ilmu Kesehatan Jenderal Achmad Yani Yogyakarta; 2016.

[19] Munawwaroh A. Fenomena Pernikahan Duda dengan Gadis untuk Membentuk Keluarga Sakinah di Kecamatan Kedukandang Malang. Skripsi. Malang: Fakultas Syari'ah Universitas Islam Negeri Maulana Malik Ibrahim; 2017.

[20] Mardiani. Sikap Ibu Hamil Trimester III tentang Persiapan Persalinan di Puskesmas Puuwatu Kota Kendaritahun. Skripsi. 2017. Sulawesi Tenggara: Politeknik Kesehatan Kendari; 2017.

[21] Lewis S, Lee A, Simkhada P. The Role of Husbands in Maternal Health and Safe Childbirth in Rural Nepal: A Qualitative Study. BMC Pregnancy and Childbirth. 2015; 15(162):1-10.

[22] Rinata E, Andayani GA. Karakteristik Ibu (Usia, Paritas, Pendidikan) dan Dukungan Keluarga dengan Kecemasan Ibu Hamil Trimester III. Jurnal IImiah IImu-ilmu Kesehatan. 16(1): 14-20.

[23] Putranti VP. Hubungan Pengetahuan dan Sikap tentang Persalinan dengan Kesiapan Primigravida menghadapi Persalinan. Tesis. Surakarta: Program Pascasarjana Universitas Sebelas Maret Surakarta; 2014.

[24] Astuti Y, Widayatun. Determinan Perilaku Kesehatan lbu pada Masa Kehamilan Kasus Kota Medan. Jurnal Kependudukan Indonesia. 2018; 13(1): 39-54.

[25] Sumiati, Dode S, Syafaraenan. Faktor- 
Faktor yang Mempengaruhi Kesiapan Ibu Hamil dalam Menghadapi Persalinan di Ruang Bersalin Rumah Sakit Umum Labuang Baji Makassar. Jurnal IImiah Kesehatan Diagnosis. 2015; 5(6): 1-7.

[26] Devy SR, Haryanto S, Hakimi $M$, Prabandari YS, Mardikanto T. Perawatan Kehamilan dan Perspektif Budaya Madura di Desa Tambak dan Desa Rapalaok Kecamatan Omben Kabupaten Sampang. Naskah Publikasi. Yogyakarta: Fakultas Kedokteran Universitas Gajah Mada; 2011.

[27] Utami FT. Penyesuaian Diri Remaja Putri yang Mneikah Muda. Jurnal Psikologi Islami. 2015; 1(1): 11-21.

[28] Pousada DS, Arroyo D, Hidalgo L, PerezLopez FR, Chedraui P. Depressive Symptoms and Resilience among Pregnant Adolescent: a case-control study. Hindawi Publishing Corporation Obstetrics and Gynecology International. 2010; 3.

[29] Rustiana D. Gambaran Dukungan Suami pada Ibu Hamil Trimester III dalam Melakukan Pemeriksaan Kehamilan di Puskesmas Banguntapan II Kabupaten Bantul. Naskah Publikasi. Yogyakarta: Sekolah Tinggi Ilmu Kesehatan Jenderal Achmad Yani; 2016.
[30] Widiarti F. Hubungan Dukungan Suami dengan Kecemasan Ibu Hamil Trimester III Dalam Menghadapi Persalinan di BPS Istri Utami Sleman. Naskah Publikasi. Yogyakarta: Fakultas IImu Kesehatan Universitas 'Aisyiyah Yogyakarta; 2017.

[31] Aminullah MR. Gambaran Tingkat Kecemasan Suami terhadap Persiapan Persalinan Istri di Wilayah Kerja Puskesmas I Baturaden. Naskah Publikasi. Sumatera Selatan: Fakultas IImu Kesehatan Universitas Muhammadiyah Palembang; 2017.

[32] Kurniasari D, Astuti YA. Hubungan Antara Karakteristik Ibu, Kondisi Bayi dan Dukungan Sosial Suami dengan Postpartum Blues pada lbu dengan Persalinan SC di Rumah Sakit Umum Ahmad Yani Metro Tahun 2014. Jurnal Kesehatan Holistik. 2015; 9(3): 115-125.

[33] Riftana FDC. Hubungan Tingkat Pengetahuan tentang Kehamilan Risiko Tinggi dengan Persiapan Persalinan pada Ibu Hamil Usia Remaja di Wilayah Kerja Puskesmas Bangsalsari Kabupaten Jember. Skripsi. Jember: Program Studi IImu Keperawatan Universitas Jember; 2013. 